Article

\title{
The Spatial Distribution, Influencing Factors, and Development Path of Inbound Tourism in China-An Empirical Analysis of Market Segments Based on Travel Motivation
}

\author{
Heping Huang ${ }^{1, *}$, Wei Zhong ${ }^{1}$, Qingsheng Lai ${ }^{2}$, Yishu Qiu ${ }^{1}$ and Hong Jiang ${ }^{1}$ \\ 1 School of Hospitality Management, Shanghai Business School, Shanghai 201400, China; \\ zhongwei@sbs.edu.cn (W.Z.); 21130018@sbs.edu.cn (Y.Q.); 21090191@sbs.edu.cn (H.J.) \\ 2 School of Economics, Fudan University, Shanghai 200433, China; laiqingsheng@fudan.edu.cn \\ * Correspondence: hhping8805@163.com or huanghp@sbs.edu.cn
}

Received: 21 February 2020; Accepted: 15 March 2020; Published: 23 March 2020

check for updates

\begin{abstract}
According to China's tourism statistics, the inbound tourism market is composed of eight types of travel motivations (sightseeing, leisure, business meeting (business-m), visiting relatives and friends (visiting-rf), shopping, religious worship (religious-w), culture and sports (culture-s), and health care (health-c)), and the spatial distribution of each type of travel motivation is significantly different. Four inbound sub-markets (foreigners, Hong Kong, Macao, and Taiwan) were selected as our research object. Through empirical analysis of the variable elasticity of eight different inbound motive market segments, we found that the sensitivities (elasticity) of the influencing factors (traffic conditions (traffic-c), destination image (destination-i), industry structure (industry-s), infrastructure, consumer price index (CPI), resource endowment (resource-e), and dressing index (ICL)) are different. Therefore, investment options in the target market can have differential treatment based on the rate of marginal return on investment. In accordance with the characteristics of different market segments, we suggest more feasible development paths and countermeasures, providing a decision-making basis for the accurate development of the inbound tourism market.
\end{abstract}

Keywords: inbound tourism; travel motivation; spatial distribution; market segments; influencing factors; elasticity; development path

\section{Introduction}

The scale of inbound tourism is an important indicator that directly reflects a country's overall competitiveness in the international tourism market [1]. The spatial and temporal distribution of tourists after entry reflects the difference in the relative competitiveness among different regions within a country [2]. The factors influencing regional competitiveness also influence the distribution of inbound passenger flow. Non-uniform distribution of tourists with eight inbound motivations (sightseeing, leisure, business meeting, visiting relatives and friends, shopping, religious worship, culture and sports, and health care) in spatial and temporal dimensions [3] has various implications for the development of the tourism industry [4]. In this study, based on spatial distribution after the entry of tourists, we systematically analyzed the influencing factors and forming mechanism of the distribution of inbound tourist flow in China from two aspects: tourist motivation and destination characteristics. We propose a clear path and strategies for the development of the Chinese inbound tourism market.

China's inbound tourism market consists of foreigners as well as visitors from Taiwan, Hong Kong, and Macao. For the past few years, the market growth of outbound and inbound tourism in China 
changed markedly. According to the Ministry of Culture and Tourism of China and the World Tourism Federation [5,6], in 2018, the number of outbound tourists who were Chinese citizens increased by $14.7 \%$ compared with the same period in the previous year. In sharp contrast, the growth rate of inbound tourists was slow, only $1.2 \%$ [7]. The number of tourists from Hong Kong decreased by $0.5 \%$. Based on the market structure formed by the eight motives in China's tourism statistics, we analyzed the significant factors influencing different travel motivation market segments, calculated and ranked the elasticity indexes of different influencing factors, and propose clear paths and strategies for the development of the inbound tourism market in different regions of China based on elasticity.

Some tourists become interested in a certain country first [8]; after choosing a specific country as the destination, they select specific scenic spots. Other tourists are first attracted by a specific scenic spot [9], so they choose to travel to a certain country. The factors that affect tourists' travel decisions before entering a country are not the same as those that affect tourists' choice of specific travel routes within a country after entry. The factors in the two stages have both common and different parts [10]. Factors such as the visa system [11], government promotion [12], climate comfort, and country image $[13,14]$ play major roles in tourist decision-making before entry. After entry, the factors influencing international tourists' travel decisions are similar to those of domestic residents, mainly focusing on the characteristics of the destination [15,16], tourist motivation, and preference [17]. Tourist motivation and destination attributes constitute the thrusting and pulling forces of inbound tourist route selection, and a strong correlation exists between them [4]. The temporal and spatial fluctuation of inbound tourist flow is the comprehensive result of many dynamic changes in influencing factors, which can be understood from multiple perspectives [18]. Regional differences among destinations in terms of economic, cultural, infrastructure, destination image [19], and tourism resource endowments are the key reasons for the scale and distribution of inbound passenger flow $[7,20]$. For this reason, many disputes remain around the cause, performance, and influence of the spatial and temporal distributions of inbound tourist flow. Xuegang [21] thought that temporal and spatial changes are imbalanced phenomena that include a time dimension, spatial dimension, and variable dimensions. We adopted this view to identify and measure the market structure and potential of China's inbound tourism market and design the corresponding accurate and highly feasible development path from the perspective of tourism motivation segmentation.

The spatiotemporal dimension is the most common perspective for the changes in China's inbound tourism market; the time dimension is mainly reflected in the variation trend of inbound tourist flow between different months, seasons, and years. The spatial dimension manifests as the direction of inbound tourist flow and the spatial agglomeration in different regions. Based on the statistical data of the quantitative distribution of the inbound tourist flow in 31 provinces and autonomous regions in China from 2009 to 2018, its fluctuations are shown in Figure 1.

The four curves in Figure 1 show the spatial distribution pattern of four inbound tourist flow markets of foreigners, Hong Kong, Macao, and Taiwan in the 31 provinces and autonomous regions of China.

The factors forming the spatial and temporal distribution of inbound tourist flow are numerous and complicated, with mutual cause and effect relationships and mutual restraint. To design an effective and feasible development path and strategy of inbound tourism market potential, we systematically mined the forming factors in depth [22]. The different sensitivity (elasticity) of influencing factors caused by different motivations was the starting point and objective for the research on the potential development strategy of the inbound tourism market.

Figure 1 only shows the spatial distribution of foreigners, Hongkonger tourists, Taiwanese tourists, and Macanese tourists in 31 provinces and autonomous regions of China. Tourists from the four source regions have eight kinds of travel motives, and the travel motive structure of each source region is different. Our research object was the 32-dimensional sample data generated by the four tourist source regions multiplied by the eight travel motivations. The resource endowment, destination image, traffic conditions, industrial structure, and climate of the destination influence tourist selection behavior. 
To fully develop the market potential of inbound tourism, we focused on the tourism motivation of inbound passengers to analyze the difference of changing elasticity of various influencing factors [7] and to precisely recognize and develop the inbound tourism market. We aimed to, (1) from the perspective of destination development and according to the influence intensity (elasticity) of each influencing factor, determine the specific development sequence and implementation path for each destination region (provinces, municipalities, and autonomous regions) and provide a decision-making basis for government investment and (2) from the perspective of source market development and according to the positioning and resource endowment characteristics of each region, suggest the strategies and implementation paths of eight kinds of motivation for market segment development for the destination region.

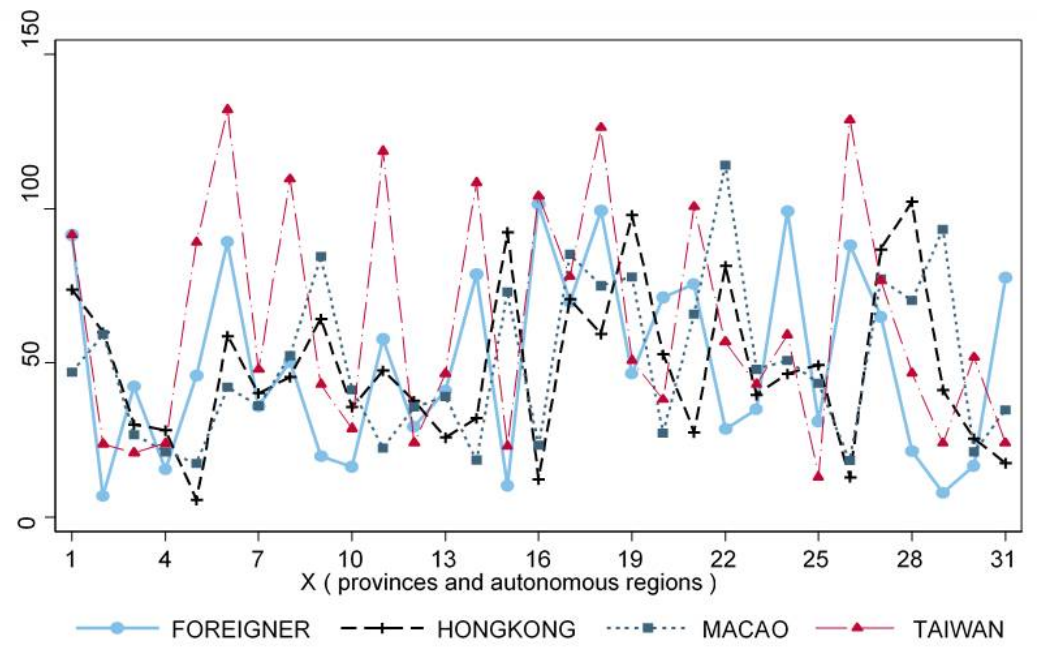

Figure 1. Inbound tourist distribution in different provinces of China (mean for 2009-2018) (Note: the regions represented from 1 to 31 are Anhui, Beijing, Fujian, Gansu, Tibet, Guangxi, Guangdong, Guizhou, Hainan, Hubei, Jiangsu, Zhejiang, Yunnan, Shandong, Shaanxi, Chongqing, Heilongjiang, Jilin, Hebei, Hunan, Sichuan, Qinghai, Xinjiang, Tianjin, Jiangxi, Inner Mongolia, Ningxia, Henan, Shanxi, Liaoning, and Shanghai, respectively).

\section{Literature Review}

The unbalanced distribution of tourists in time, space, and other variables has become one of the bottlenecks of tourism development, which has been a popular academic research focus. The individual attributes of tourists, the characteristics of the tourist generating region, destination features, and other environmental factors significantly impact the unbalanced distribution of tourist flow [23-25] in both the time and spatial dimensions. On the tourism supply side, the importance of the destination market's "demand to undertake" is self-evident [26]. The full development of the supply side of the destination market is one of the important aspects to achieve a balanced development of the inbound tourism industry in China [27].

The research on the tourist flow of the destination started in the 1990s. The time and spatial dimensions were commonly used to study the unbalanced distribution of tourist flow. Taking the Jiuzhaigou valley as the research object, Jie and Jinkang [28] verified the spatial distribution of tourism demand and calculated the attenuation index and obtained the optimal Pareto model. Lin [29] took Sanya, Beihai, Mount Putuo, Mount Huang, and Mount Jiuhuashan as examples to study the seasonal characteristics of the tourism industry of the beach- and mountain-type destinations in the time dimension, from some perspectives such as price leverage, tourism product development, special market development (e.g., grey-haired market), and media publicity strategy, and then proposed the response measures for the seasonal natural causes and social causes. Based on the time and space compression effect of China's high-speed rail development, Degen [30] took Mount Tai and 
Mount Hengshan as examples, which are located along the Beijing-Guangzhou railway line and the Beijing-Shanghai railway line. Degen empirically analyzed the temporal and spatial changes in the domestic tourism demand structure. The results showed that the market share of the short-range market significantly reduced; the tourism source market, which ranged from 750 to $1000 \mathrm{~km}$, significantly improved; and overall, more than $60 \%$ of the destination underwent obvious changes in attracting the tourist market. This conclusion further supports the important influence of traffic conditions on the spatial and temporal distribution of tourist flow. Zehua [31] selected Golden Week, winter and summer holidays, and six other different periods of leisure time to perform an in-depth study on the changing source structure of the Sun Yat-sen cemetery. The results showed that the length of leisure time and climate environment directly affect the scenic passenger flow and the consumption level, followed by economic constraints (per capita GDP of the source countries) [32]. Based on the inbound tourism development strategy, Tokumulashise [33] took Japanese tourists who visit China as the research object. Through analysis of market attributes, structure evolution, and age change, the necessity and feasibility of developing the potential Japanese tourist market in China were outlined, and some suggestions and countermeasures for the related difficulties were suggested. Perspectives such as tourists' preferences [34], tourist-generating region, destination image [35-38], types of scenic spots, comfort index of climate [39], spatial distance, prices [40], and some other perspectives have been reported in the literature.

Studies of travel motives have been extensive [3,41]. Early in the 1930s, Huxley began to analyze the tourism motive, emphasizing the impact of tourism on the growth of knowledge and broadened thinking. In 1982, Pearce provided a comprehensive account of travel motivations from the perspective of social psychology. Since then, travel motives as a professional term is widely used in academia. The tourism market is commonly divided on the perspective of tourists' travel motives. Juergen and Metin [42,43] proposed the match between the motive and the expected value of traveling; their results showed that the expectations of different tourists have obvious differences. Subsequently, Juho [44] proved this in the rural tourism market. Elizabeth and Dunn [45] analyzed tourist sample data and found that sightseeing passenger flow has consistency in travel motivation and satisfaction. Mara and Duk $[46,47]$, through empirical studies of the rural tourism market, confirmed the critical role of motivation in determining visitors' choices. On this basis, Yooshik [48] applied a structural model to verify the significant positive correlation between travel motivation, satisfaction, and visitor loyalty. Honglei et al. constructed a logistic model with discrete choice containing interaction terms and analyzed different consuming behaviors of diverse motivations. They found that the consumption capacity of tourists who are looking for leisure and a comfortable environment is significantly higher than those who visit relatives and friends, whereas business travelers tend to choose long-distance destinations [49]. From the perspective of destination, Wei et al. [50] analyzed the temporal and spatial distribution characteristics of tourist flow in specific periods in Wuhan, and concluded that tourists with different travel purposes (sightseeing tour, visiting relatives and friends, business meeting, shopping and leisure, etc.) exhibit significant differences in seasonal distribution, and thus could predict the response patterns of different regions.

In general, since academics have completed detailed studies on regional distribution, the time and space structure of the tourism industry, and the relationship between travel motives and behavior [37], researchers have already focused on the difference in preferences, influencing factors, elasticity, consumer behavior, and other aspects of tourists with different tourism motivations. However, the existing literature based on tourist travel motives is still scattered, as are the studies on market potential with diverse tourism motivations. Following Wei's research idea, we first quantified the regional market potential of the different travel motivation market segments (sightseeing, shopping, leisure, business meetings, visiting relatives and friends, religious worship, etc.) in the inbound tourism market (foreigners, Hongkonger tourists, Macanese tourists, and Taiwanese tourists) of China. We combined elasticity differences of various motivations, which are caused by different variables such as traffic conditions [51,52], consumer price index (CPI) [53], resource endowments, destination 
image [54,55], climate environment, industrial structure, and infrastructure [56] to explore the market potential development model and path that suits the unbalanced distribution of inbound tourist flow in provinces and autonomous regions. Finally, we propose countermeasures and suggestions that are more practical.

\section{Data Sources and Research Methods}

Based on China's 31 provinces and city autonomous regions, which are municipalities directly under the central government, as the study area, we divided the inbound passenger flow into four sub-markets. Tourist flow data were obtained from the China Tourism Statistics Yearbook from 2009 to 2018, China Statistical Yearbook, and the government's official website in each administrative area, using the industry classification methods of the China Statistical Yearbook. Due to slight differences in the statistical caliber of tourism indicators in various provinces and autonomous regions, and changes in the statistical caliber of tourism statistical yearbooks from 2009 to 2018, the indicators were merged and sorted. For some administrative areas with missing data, we conducted a field survey to obtain accurate relevant data for cleaning, calculating, and sorting, and finally obtained statistical data that satisfied our research purpose.

In terms of research methods, our study was based on existing research results; using a literature review and statistics, we selected the factors affecting the spatial distribution of passenger flow. On this basis, the stepwise regression method was used to analyze the related influencing factors [57] to finally determine the inbound passenger flow spatial econometric model and obtain the elastic coefficient index of relevant variables. We then applied geography spatial agglomeration, such as the space Gini coefficient and location entropy, to build inbound tourism destination spatial distribution index [58-60]. The specific calculation path is shown in Section 4.3. Figure 2 depicts a theoretical logic diagram of our research process.

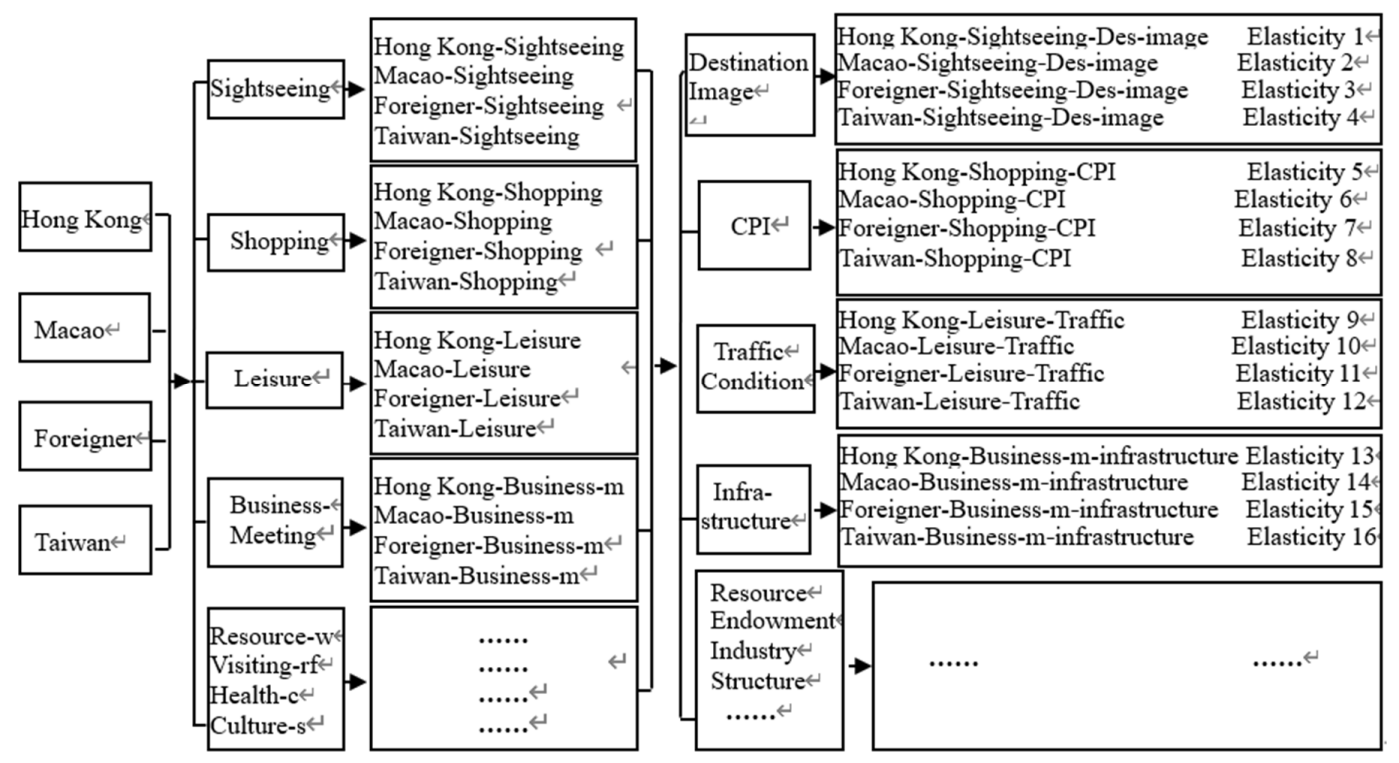

Figure 2. The theoretical logic diagram of our research process. The four inbound tourist markets consist of eight travel motivations of tourists, forming $4 \times 8=32$ dimensions of sample data. The tourist flow in each dimension is influenced by variables such as traffic conditions, infrastructure, and destination image, and the degree of influence is obviously different, which provides an important basis for accurate development of different sub-markets of inbound tourism. List of motivations: sightseeing, leisure, business meeting (business-m), visiting relatives and friends (visiting-rf), shopping, religious worship (religious-w), culture and sports (culture-s), and health care (health-c). List of influencing factors: traffic conditions (traffic-c), destination image (destination-i), industry structure (industry-s), infrastructure, consumer price index (CPI), resource endowment (resource-e), and dressing index (ICL). 


\section{Empirical Study on Destination Potential of Inbound Tourism Market}

Although the literature provides various corresponding methods for unbalanced phenomena of tourism activities on the destination market, these ideas are not strong in practice and lack pertinence, which seriously restrict potential mining and accurate development of the destination market. Many factors influence the tourist distribution in the destination market, but how can we find the entry point of the potential development? What are the specific development models and technical paths? How do we realize the effective allocation of tourism resources in the whole country? A series of practical problems beset the process of developing the potential of the destination tourism market. To solve the unbalanced distribution of inbound passenger flow, which has troubled the tourism industry for many years, and to release the special industry bonus, this study was based on the differences in sensitivity of each variable element (elasticity) in the market segment, through empirical analysis of the factors influencing the supply side of the destination to provide a more feasible operation model and countermeasures and suggestions for the inbound tourism potential development of the destination market. In this paper, the sensitivity (elasticity) of different market segments of travel motivation to each influencing factor is the key to the potential development strategy for the destination market.

Figure 3 shows the proportion structure of eight types of tourist motivations of inbound passenger flow, demonstrating the significant differences in the size and distribution of tourists with different tourist motivations.

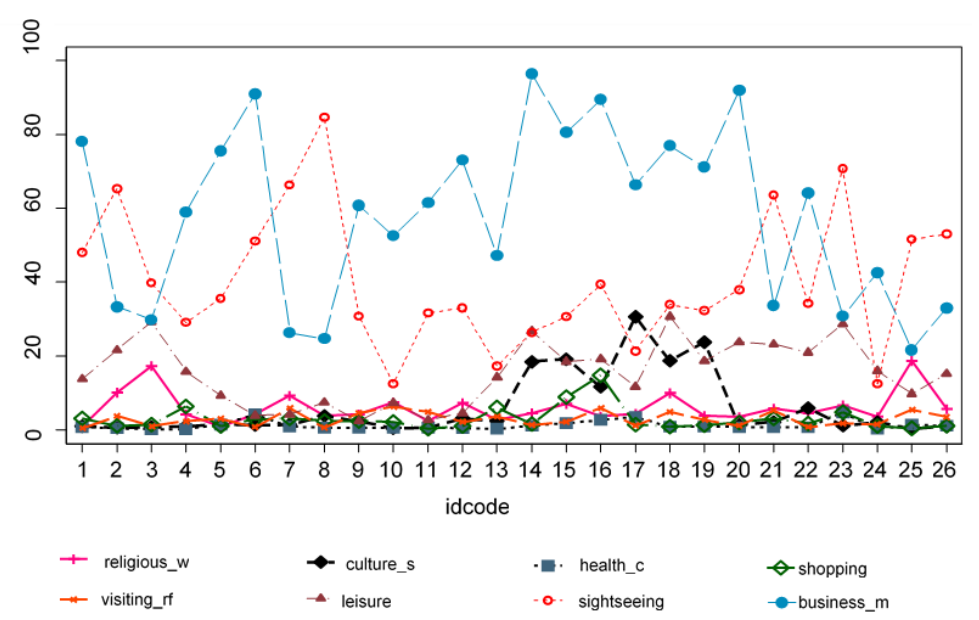

Figure 3. Inbound tourist flow structure of destination regions based on different motives (mean of 2009-2018).

\subsection{Analysis of the Structure of Inbound Tourist Flow in Provincial Destinations}

China's tourism statistics divide tourism motivations into eight categories: sightseeing, shopping, leisure, business meeting, visiting relatives and friends, religious worship, culture and sports, and health care. Based on the data of the inbound passenger flow in each province and autonomous region from 2009 to 2018, the dynamic trend in different travel motive market segments is shown in Figure 3. The unbalanced distribution of China's inbound tourist flow varies for different travel motives. First, in terms of the proportion structure of total tourist flow, sightseeing and business meetings accounted for the largest proportion, followed by leisure and religious worship, culture and sports, and visiting relatives and friends ranked third; culture and sports and shopping had the lowest proportion. Second, the distribution of inbound tourist flow for different travel motives was obviously different among different destination regions. Third, the tourist motivation structure of the four sub-markets (foreigners, Hongkonger tourists, Macanese tourists, and Taiwanese tourists) were also different in different destination regions. The differences in scale structure based on different market 
segments, motivations, and variables provide an important basis for developing a more operational inbound tourism market development strategy.

\subsection{Inbound Tourism Potential Development Model in Provincial Destination}

Based on the current development of China's inbound tourism, the actual development situation of each province and autonomous region is different. Due to limited resources, the resources that can be devoted to the tourism industry are low, so we considered marginal revenue. To identify a potential development path for the nationwide destination supply market that is the most effective and direct for inbound passengers, we aimed to determine the distribution of the inbound tourism market potential for each variable across the country (such as traffic conditions, industrial structure, climate environment, consumer price index, resources endowment, destination image, and infrastructure). The areas with relatively large development potential for phased development should be prioritized to maximize the efficiency of resource allocation.

\subsubsection{Sensitivity Analysis of Different Motivations to Different Variables}

We selected influencing factors mainly based on two aspects: market investigation and survey on the motivation of inbound tourists to visit China, and a literature review of CNKI and Science-Direct, selecting the seven elements with the highest frequency, which could be understood as variable factors that have achieved consensus amongst academics as influencing factors. On this basis, statistical data for 31 provinces and autonomous regions from 2009 to 2018 were selected for panel data regression analysis. The elastic regression results are shown in Table 1.

Table 1. Sensitivity coefficient of influencing factors of spatial distribution of inbound tourists. Source: Authors' elaboration.

\begin{tabular}{cccccccc}
\hline Factors & $\begin{array}{c}\text { Climate } \\
\text { ICL }\end{array}$ & $\begin{array}{c}\text { Industry } \\
\text { Structure }\end{array}$ & $\begin{array}{c}\text { Traffic } \\
\text { Condition }\end{array}$ & $\begin{array}{c}\text { Price } \\
\text { Index CPI }\end{array}$ & $\begin{array}{c}\text { Resource } \\
\text { Endowment }\end{array}$ & $\begin{array}{c}\text { Destination } \\
\text { Image }\end{array}$ & $\begin{array}{c}\text { Infra- } \\
\text { Structure }\end{array}$ \\
\hline Sightseeing & $0.191^{* *}$ & $0.019^{* * *}$ & $0.478^{* * *}$ & $0.439^{* *}$ & $0.541^{*}$ & $0.511^{* *}$ & $0.528^{* *}$ \\
Shopping & $0.177^{* *}$ & $0.053^{* * *}$ & $0.596^{* * *}$ & $0.411^{* * *}$ & $0.031^{*}$ & $0.526^{* * *}$ & $0.502^{* *}$ \\
Leisure & $0.415^{* * *}$ & $0.131^{*}$ & $-0.068^{*}$ & $0.197^{* * *}$ & $0.438^{*}$ & $0.214^{* * *}$ & $0.026^{*}$ \\
Business-m & $0.008^{*}$ & $0.166^{* *}$ & $0.296^{* *}$ & $-0.115^{*}$ & $0.065^{* *}$ & 0.018 & $0.236^{* * *}$ \\
Resource-w & $0.009^{* *}$ & $0.026^{*}$ & $0.284^{*}$ & $0.051^{* *}$ & $0.052^{*}$ & $-0.026^{* *}$ & $0.007^{* *}$ \\
Visiting-rf & $0.134^{* *}$ & $0.018^{*}$ & $0.272^{* *}$ & $0.103^{* *}$ & $0.073^{* *}$ & $0.112^{*}$ & 0.132 \\
Health-c & $0.511^{* * *}$ & $0.092^{*}$ & $0.251^{* *}$ & $0.127^{* *}$ & $0.129^{*}$ & $0.127^{* *}$ & $0.130^{* * *}$ \\
Culture-s & $0.205^{* *}$ & $0.271^{* *}$ & $0.161^{* *}$ & $0.105^{* *}$ & $0.357^{* *}$ & $0.308^{* *}$ & $0.227^{* *}$ \\
\hline
\end{tabular}

From Table 1, the majority of the regression results were significant at the $10 \%$ level of significance. Only the categories visiting relatives and friends, business meeting, and culture and sports were not significant in the variables of infrastructure, destination image, and industry structure. Therefore, for the purposes of our study, these regression results are significant and could be used as a basis for further research.

\subsubsection{Inbound Tourism Potential Development Strategy of Different Motivation Market Segments}

For different destination regions, the characteristics of the inbound tourist flow structure should be identified first. For variables that are not subject to human will but were relatively weak in the region, that is, for variables that cannot be changed artificially, we started with tourism motivation and selected the travel market segment that is not sensitive to this variable for targeted development. For variables that can be changed through acquired investment and effort, we considered them from two aspects: the improvement of the quality of the variable and the planned cultivation and development of different travel motivation market segments. Based on the regression results above, we ranked the elastic values of various influencing factors in different market segments of travel motivation, as shown in Table 2. 
Table 2. The value of elasticity intensity from the segment of travel motivation.

\begin{tabular}{|c|c|c|c|c|c|c|c|c|}
\hline \multirow{2}{*}{$\frac{\text { Influencing Factor }}{\text { ICL }}$} & \multicolumn{8}{|c|}{ Elastic Strength of Variables for Different Travel Purposes (Elasticity Decreases from Left to Right) } \\
\hline & $\begin{array}{c}\text { Health-c } \\
0.511\end{array}$ & $\begin{array}{l}\text { Leisure } \\
0.415\end{array}$ & $\begin{array}{l}\text { Culture-s } \\
0.205\end{array}$ & $\begin{array}{c}\text { Sightseeing } \\
0.191\end{array}$ & $\begin{array}{c}\text { Shopping } \\
0.177\end{array}$ & $\begin{array}{l}\text { Visiting-rf } \\
0.134\end{array}$ & $\begin{array}{l}\text { Religion-w } \\
0.009\end{array}$ & $\begin{array}{c}\text { Business-m } \\
0.008 \text { (weakening) }\end{array}$ \\
\hline Industry Structure & $\begin{array}{c}\text { Culture-s } \\
0.271\end{array}$ & $\begin{array}{c}\text { Business-m } \\
0.166\end{array}$ & $\begin{array}{c}\text { Leisure } \\
0.131\end{array}$ & $\begin{array}{c}\text { Health-c } \\
0.092\end{array}$ & $\begin{array}{c}\text { Shopping } \\
0.053\end{array}$ & $\begin{array}{l}\text { Religion-w } \\
0.026\end{array}$ & $\begin{array}{c}\text { Sightseeing } \\
0.019 \\
\end{array}$ & $\begin{array}{c}\text { Visiting-rf } \\
0.018 \text { (weakening) }\end{array}$ \\
\hline Traffic condition & $\begin{array}{c}\text { Shopping } \\
0.596\end{array}$ & $\begin{array}{c}\text { Sightseeing } \\
0.478\end{array}$ & $\begin{array}{l}\text { Business-m } \\
0.296\end{array}$ & $\begin{array}{l}\text { Religion- } \mathrm{w} \\
0.284\end{array}$ & $\begin{array}{l}\text { Visiting-rf } \\
0.272\end{array}$ & $\begin{array}{c}\text { Health-c } \\
0.251\end{array}$ & $\begin{array}{c}\text { Culture-s } \\
0.161\end{array}$ & $\begin{array}{c}\text { Leisure } \\
0.068 \text { (weakening) }\end{array}$ \\
\hline Resource Endowment & $\begin{array}{c}\text { Sightseeing } \\
0.541\end{array}$ & $\begin{array}{c}\text { Leisure } \\
0.438\end{array}$ & $\begin{array}{l}\text { Culture-s } \\
0.357\end{array}$ & $\begin{array}{l}\text { Health-c } \\
0.129\end{array}$ & $\begin{array}{l}\text { Visiting-rf } \\
0.073\end{array}$ & $\begin{array}{c}\text { Business-m } \\
0.065\end{array}$ & $\begin{array}{l}\text { Religion-w } \\
0.052\end{array}$ & $\begin{array}{c}\text { Shopping } \\
0.031 \text { (weakening) }\end{array}$ \\
\hline Destination Image & $\begin{array}{c}\text { Shopping } \\
0.526\end{array}$ & $\begin{array}{c}\text { Sightseeing } \\
0.511\end{array}$ & $\begin{array}{c}\text { Culture-s } \\
0.308\end{array}$ & $\begin{array}{l}\text { Leisure } \\
0.214\end{array}$ & $\begin{array}{c}\text { Health-c } \\
0.127\end{array}$ & $\begin{array}{l}\text { Visiting-rf } \\
0.112\end{array}$ & $\begin{array}{l}\text { Religion-w } \\
0.026\end{array}$ & $\begin{array}{c}\text { Business-m } \\
0.018 \text { (weakening) }\end{array}$ \\
\hline Price level CPI & $\begin{array}{c}\text { Sightseeing } \\
0.439\end{array}$ & $\begin{array}{c}\text { Shopping } \\
0.411\end{array}$ & $\begin{array}{c}\text { Leisure } \\
0.197\end{array}$ & $\begin{array}{l}\text { Health-c } \\
0.127\end{array}$ & $\begin{array}{l}\text { Business-m } \\
\quad 0.115\end{array}$ & $\begin{array}{l}\text { Culture-s } \\
0.105\end{array}$ & $\begin{array}{l}\text { Visiting-rf } \\
0.103\end{array}$ & $\begin{array}{c}\text { Religion-w } \\
0.051 \text { (weakening) }\end{array}$ \\
\hline Infrastructure & $\begin{array}{c}\text { Sightseeing } \\
0.528\end{array}$ & $\begin{array}{c}\text { Shopping } \\
0.502\end{array}$ & $\begin{array}{l}\text { Business-m } \\
0.236\end{array}$ & $\begin{array}{c}\text { Culture-s } \\
0.227\end{array}$ & $\begin{array}{l}\text { Visiting-rf } \\
0.132\end{array}$ & $\begin{array}{c}\text { Health-c } \\
0.130\end{array}$ & $\begin{array}{c}\text { Leisure } \\
0.026\end{array}$ & $\begin{array}{c}\text { Religion-w } \\
0.007 \text { (weakening) }\end{array}$ \\
\hline
\end{tabular}


Table 2 shows that the empirical results are basically consistent with our theoretical expectations. Different market segments of travel motivation have different elastic strengths on various influencing factors, and the difference is significant. According to the marginal diminishing principle of resource utilization efficiency, for each market segment based on travel motivation, our development sequence should be consistent with the sequence of elastic strength.

At this point, for a specific destination region, if the entry point is chosen as the variable dimension, at least two aspects should be considered: the factors that cannot be changed through acquired efforts, such as climate and environment, and the factors that can be promoted through acquired efforts, such as traffic conditions. Specific to a particular destination, the development of a certain market segment of a destination region (such as sightseeing, shopping, leisure, or business meeting) should be based on the actual development of the region according to the elastic strength of different variables to determine the development sequence of the variables. However, the marginal output of different variable dimensions is a dynamic process that requires measurement tracking in stages.

\subsection{Destination Market Potential Measure of Inbound Tourism}

Combined with the weighted average method, we introduce the market structure weight index. The index is based on the proportion of different travel motivation market segments in the whole tourism market, and we obtained specific development potential values of different regions. By taking the proportion of the tourist flow of the eight travel motivations as the weight and multiplying by the elasticity coefficient of the eight travel motivations to variables, the weighted average value obtained is used to indicate the comprehensive development potential of the inbound tourism market in this region. This calculation path was applied to foreigners, Hongkonger tourists, Taiwanese tourists, and Macanese tourists. Thus, the distribution of potential of each inbound sub-market (foreigners, Hongkonger tourists, Macanese tourists, and Taiwanese tourists) in each destination region was obtained. The specific indexes are calculated as follows:

$$
\begin{gathered}
\mathrm{D}_{n i}=\sum_{m=1}^{6} \mathrm{~K}_{i m} * W_{m n} \\
\mathrm{D}_{n m}=\sum_{i=1}^{7} \mathrm{~K}_{i m} * W_{m n} \\
\mathrm{D}_{n}=\sum_{i=1}^{7} \sum_{m=1}^{6} \mathrm{~K}_{i m} * W_{m n}
\end{gathered}
$$

where $i$ represents the variable of influencing factor, $m$ indicates motivational segmentation, $n$ represents the provinces and autonomous regions, and $\mathrm{K}$ is the response strength index of each travel motivation segment market to each influencing variable, which means $\mathrm{K}_{i m}$ indicates the flexibility of the $m$ th motivational market (such as sightseeing) to the $i$ th variable (such as traffic conditions), which is the change in visitor numbers caused by the change in $i$ per unit. $W_{m n}$ indicates the market weight of the $m$ th tourism motivation market segment in the $n$th province and autonomous region. Equation (1) shows the market potential space of a certain destination (province or autonomous region) in each variable dimension (influencing factor). Equation (2) shows the scale of the market potential of a destination (province or autonomous region) in the $m$ th travel market segment (such as sightseeing). Equation (3) shows the total potential of a certain destination (province or autonomous region) in all market segments and all variable dimensions. To more clearly describe the regional distribution of market potential in different sub-markets of inbound tourist flow, we drew the distribution patterns of the market potential in the four sub-markets, as shown in Figure 4. The potential we calculated is the sum of the potential of all variables and travel motive segments. 


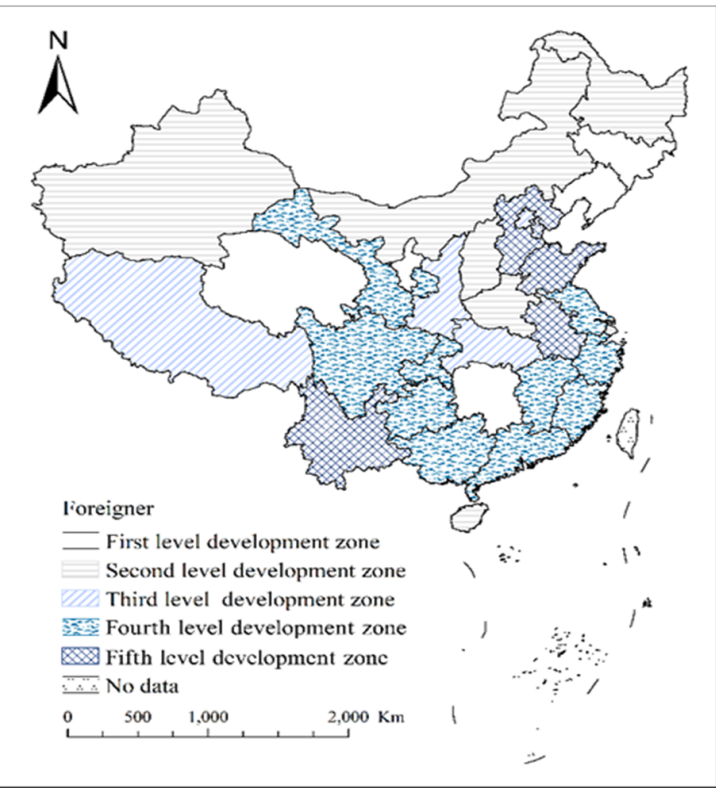

(a)

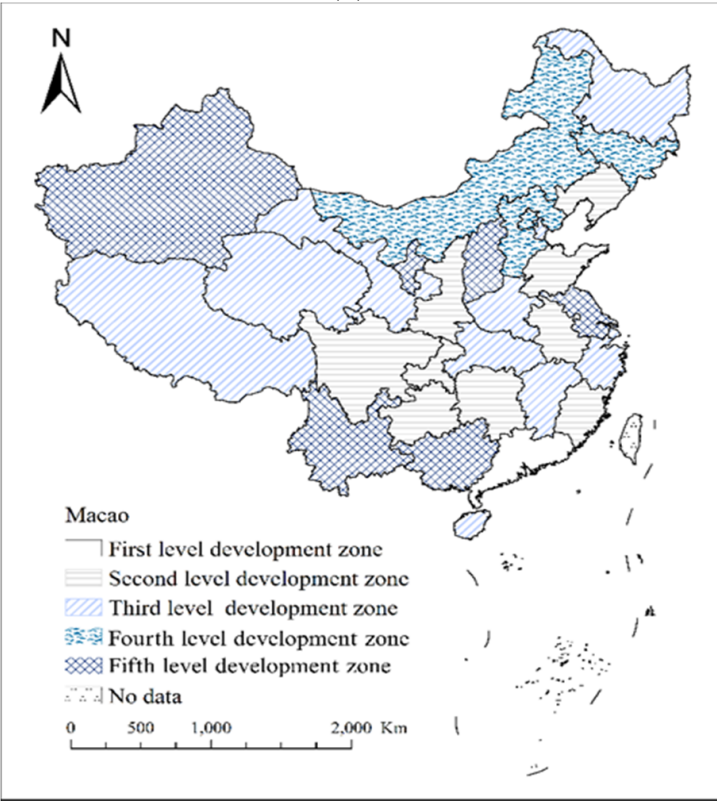

(c)

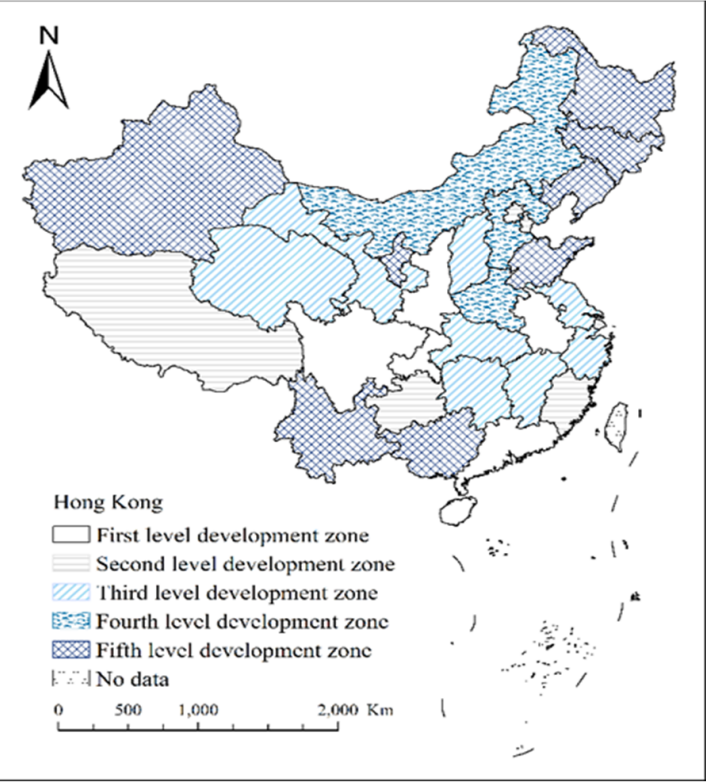

(b)

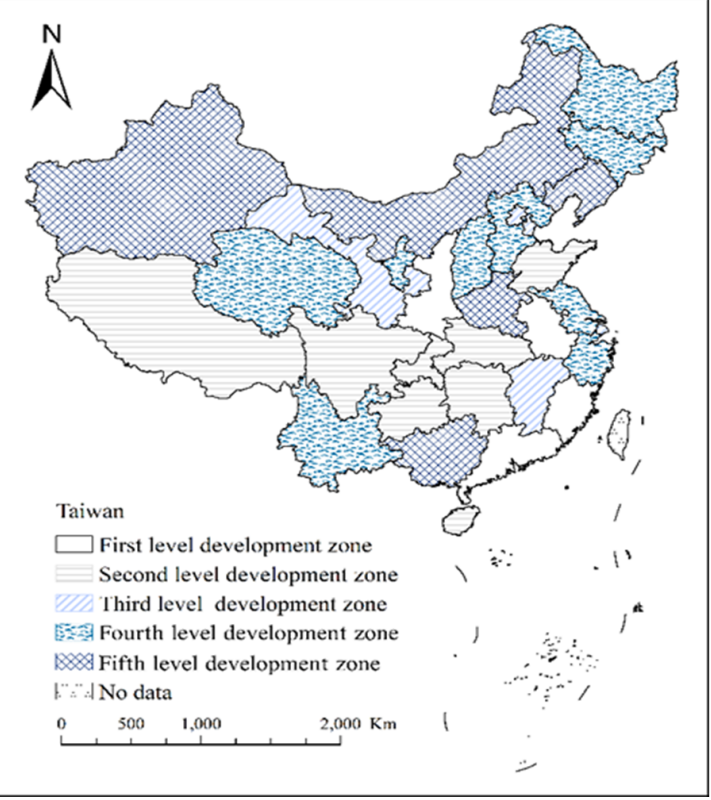

(d)

Figure 4. Potential distribution of tourism market in 31 destinations for foreigners and visitors from Macao, Hong Kong, and Taiwan, with the comprehensive value of inbound tourism potential of different regions calculated according to Equations (1)-(3) that reflects the development potential of inbound tourism in this region. The value is divided into five levels and displayed with different signs in the figure. Distribution of (a) foreign, (b) Hong Kong, (c) Macao, and (d) Taiwan tourism market potential.

\subsection{Path Design of Developing Inbound Tourism Market Potential}

According to the elastic value of different travel motivation segments to different influencing variables, we designed the development path of the market potential of each inbound tourist flow sub-market to obtain the development sequence and response intensity of each variable. Due to paper length limitations, only the destination regions with the most potential in each passenger flow sub-market are presented, and similar analysis can be applied to the other destination regions according to this idea. 
Through the systematic analysis of Table 3, we found that the potential areas of different inbound tourist sub-markets (foreign, Hongkonger, Macanese, and Taiwanese tourists) are not the same. The four selected regions are typical representatives of China's developed regions such as Shanghai, as well as the less developed regions in the west (Yunnan province). The conclusions in Table 3 validate our theoretical expectations of the intensity of the influencing factors in a diverse tourism market being unstable in either the time or space dimension. However, this change can be used as an important basis for a more effective and targeted market development strategy. For example, resource endowment constrains inbound tourist flow in Shanghai, whereas infrastructure is the most important variable that limits the inbound tourist flow of Shandong province, and industrial structure is the primary variable of inbound tourism development in Yunnan and Henan provinces.

Table 3. The path design of the travel market potential for 31 provinces.

\begin{tabular}{|c|c|c|c|c|c|c|c|c|}
\hline \multirow{2}{*}{$\begin{array}{c}\text { Space } \\
\text { Dimension }\end{array}$} & \multirow{2}{*}{$\begin{array}{c}\begin{array}{c}\text { Potential } \\
\text { Area } \\
\text { (Value) }\end{array} \\
\text { Yunnan } \\
(1.887)\end{array}$} & \multirow{2}{*}{$\begin{array}{c}\begin{array}{c}\text { Priority } \\
\text { Index }\end{array} \\
0.378 \\
\text { Infrastructure }\end{array}$} & \multicolumn{6}{|c|}{ Developing Indices of Other Variables in Order of Potential Value } \\
\hline & & & $\begin{array}{c}0.311 \\
\text { Industry-s }\end{array}$ & $0.298 \mathrm{CPI}$ & $\begin{array}{c}0.219 \\
\text { Traffic-c }\end{array}$ & $\begin{array}{c}0.196 \\
\text { Destination-i }\end{array}$ & $0.161 \mathrm{ICL}$ & $\begin{array}{c}0.028 \\
\text { Resource-e }\end{array}$ \\
\hline $\begin{array}{l}\text { Hong } \\
\text { Kong }\end{array}$ & $\begin{array}{l}\text { Shandong } \\
(2.139)\end{array}$ & $\begin{array}{c}0.456 \\
\text { Infrastructure }\end{array}$ & $\begin{array}{c}0.396 \\
\text { Traffic-c }\end{array}$ & $\begin{array}{c}0.391 \\
\text { Destination-i }\end{array}$ & $0.311 \mathrm{ICL}$ & $\begin{array}{c}0.286 \\
\text { Resource-e }\end{array}$ & $0.126 \mathrm{CPI}$ & $\begin{array}{c}0.082 \\
\text { Industry-s }\end{array}$ \\
\hline Macao & $\begin{array}{l}\text { Shanghai } \\
(1.916)\end{array}$ & $\begin{array}{c}0.338 \\
\text { Resource-e }\end{array}$ & $\begin{array}{c}0.321 \\
\text { Destinaton-i }\end{array}$ & $0.317 \mathrm{ICL}$ & $\begin{array}{c}0.287 \\
\text { Traffic-c }\end{array}$ & $\begin{array}{c}0.258 \\
\text { Infrastructure }\end{array}$ & $\begin{array}{c}0.114 \\
\text { Industry-s }\end{array}$ & $0.076 \mathrm{CPI}$ \\
\hline Taiwan & $\begin{array}{l}\text { Henan } \\
(2.113)\end{array}$ & $\begin{array}{c}0.383 \\
\text { Industry-s }\end{array}$ & $\begin{array}{c}0.362 \\
\text { Infrastructure }\end{array}$ & $\begin{array}{c}0.358 \\
\text { Traffic-c }\end{array}$ & $\begin{array}{c}0.301 \\
\text { Resource-e }\end{array}$ & $\begin{array}{c}0.278 \\
\text { Destination-i }\end{array}$ & 0.119 CPI & $0.036 \mathrm{ICL}$ \\
\hline
\end{tabular}

\section{Discussion}

Due to the differences between destinations (province or autonomous region), the scale and flow direction of inbound tourists based on various travel motivations (sightseeing, shopping, leisure, business meeting, visiting relatives and friends, religious worship, culture and sports, health care) have a direct causal relationship with the endowment characteristics of each destination area [34,37]. The market potential of inbound tourist flow mainly depends on the attributes of the tourism supply side, such as the industrial structure, resource endowment, climate comfort index, destination image [38], price level, and traffic conditions of the destination [43,49]. More importantly, due to the differences in culture, endowment, geography, economy, policies, and other aspects among different destinations (province or autonomous region) [53-55], the tourism demand elasticity intensity of different travel motivation segments for various variables is significantly different, which is consistent with our theoretical expectations. This difference was the starting point and foothold of this study and the basis of the proposed development path.

Our research mainly included four dimensions, which were used as the primary criteria for our development strategy of the destination markets: the 31 destination areas (provinces or autonomous regions) in China, eight types of inbound tourism motivations, significant variables influencing destinations, and the features of the tourist source market (foreign, Macanese, Hongkonger, and Taiwanese tourists). For the tourism source dimension, we combined the four inbound passenger markets into a whole inbound tourism market, designing the development path in a whole market, and we analyzed the four markets individually, which means each sub-market was regarded as an inbound passenger flow market. The two approaches are exactly the same. For the other three dimensions and according to the principle of diminishing marginal output of resource use efficiency, for each market segment of travel motivation, the development order of each variable should be consistent with the order of elastic strength, which can be understood and operated from the three perspectives as follows. (1) When a specific variable (such as traffic conditions, infrastructure, etc.) is invested in and developed, the response intensity of different travel motivation segments will be different (as shown in Table 2). We can effectively develop the variable if it satisfies two conditions. The first condition is that the market segment with certain travel motivations has the greatest response strength to this variable. 
The second condition is that in the spatial dimension, the region has the maximum marginal output when investments are made in the variable. In other words, this region has a higher output than other regions. (2) For a specific market segment (for example, sightseeing or visiting relatives and friends), the operation path for its development should be consistent with the elastic strength ranking as shown in Table 1. In other words, the same type of sub-market (such as sightseeing or visiting relatives and friends) has a different potential in different regions and different influencing factors (such as traffic conditions or infrastructure) have different promoting effects on the inbound tourism sub-market. (3) For a specific destination area, the foreign, Hongkonger, Taiwanese, and Macanese tourist markets can be ranked first according to their comprehensive potential, and priority source markets can be selected for development. After that, for the overall inbound tourism market development of a specific destination (combine four inbound tourism sub-market of foreigners and visitors from Macao, Hong Kong, and Taiwan), three aspects should be considered: the center of gravity of the market structure (the proportion of inbound tourist motivation market segments), elastic strength, and the region's tourism resource endowment. Then, the development index is obtained (the calculation path and equations are shown above). Table 3 shows the areas with the most potential development for different sub-markets (foreign, Macanese, Hongkonger, and Taiwanese visitors) in China.

Notably, during the process of practical development, whether the influencing factor variables can be changed artificially must be determined. The marginal input or output of different variables measured in this paper is a relative value that also dynamically changes. For example, when continuously investing in infrastructure, the marginal output it produces must decrease beyond a certain critical value and the direction of investment should be changed (for example, divert investment to traffic conditions), which means the marginal input and output of the relative changes must be followed, and the investment direction must be adjusted and modified in stages.

Through empirical analysis, we found an important distribution rule of the market potential of inbound tourist flow. Generally, both developed and underdeveloped areas have huge inbound tourism market potential. Especially in the dimensions of infrastructure, traffic conditions, and industrial structure, the market potential of underdeveloped regions is huge. This is due to insufficient investment in underdeveloped areas, which had led to the number of inbound tourists being restricted by the objective environment. Therefore, this is one of the important directions for follow-up development. Conversely, economically developed areas have emerged as having potential for development. For example, Shanghai's tourism resource endowment is relatively weak, but with its developed economic level, excellent infrastructure, and traffic conditions, it compensates for the shortage of resources to some extent. However, a gap still exists between the current scale of inbound tourist flow and its superior conditions in various variables, which can be improved through human-made attractions such as theme parks, sports events, water tourism, and cruise tourism.

Market segments with different travel motives have differences in tourism preferences, influencing factors, and consumption behaviors. As an attempt to explore in this field, the development mode and operation path proposed in this paper are conducive to the effective and accurate development of the market potential of inbound destination tourist flow. Combined with the significant differences in inbound tourist flow in different travel motivation dimensions, this paper provides a potential measurement and development path design of inbound tourist flow, which is also the main innovation of this study.

\section{Conclusions}

The slow development of China's inbound tourism market has seriously affected the overall development of China's tourism. Inbound tourism has become an important aspect of the further development of China's tourism market. We chose visitor scale as an evaluation index of the inbound tourism market, providing important insights into the investment path choices for inbound tourism development of China's provinces and autonomous regions. The main findings were as follows. (1) For specific tourist destinations, under the original resource endowment and market conditions, 
the market potential has not been effectively developed. The inbound tourist flow may be increased by destination image enhancement, marketing strategy optimization, technological innovations, etc. In other words, this strategy can be adopted in areas where reception capacity exceeds the level of demand and market potential is not fully tapped. (2) When the existing market potential has been fully tapped, we should improve and upgrade the influence factors that can be changed artificially (such as traffic conditions, infrastructure, reception facilities, etc.) and invest in the service quality and reception capacity of the destination to improve the tourist scale, consumption, and market share of inbound passenger flow. (3) For influencing factors that have no market elasticity (e.g., climate condition) or are hard to change in the short term, the potential can be explored from the perspectives of developing and innovating featured tourism products and special target markets. For example, cold areas with low climate comfort can develop snow and ice tourism such as skiing and skating; for an area with weak reception facilities, products such as tourism exploration and wild survival can be developed.

Author Contributions: Conceptualization, H.H.; data curation, Q.L.; investigation, Y.Q.; software, W.Z.; supervision, H.J.; writing-original draft, H.H. All authors have read and agree to the published version of the manuscript.

Funding: This research was funded by The Funding of Philosophy and Social Science Planning Project of Shanghai, grant number 2018BJB021, and Philosophy and Social Science Planning Project of Ministry of education, China, grant number 20YJA790029.

Conflicts of Interest: The authors declare no conflict of interest.

\section{References}

1. Gómez-Vega, M.; Picazo-Tadeo, A.J. Ranking world tourist destinations with a composite indicator of competitiveness: To weigh or not to weigh? Tour. Manag. 2019, 72, 281-291. [CrossRef]

2. Liu, Y.; Li, Y.; Parkpian, P. Inbound tourism in Thailand: Market form and scale differentiation in ASEAN source countries. Tour. Manag. 2018, 64, 22-36. [CrossRef]

3. Deichmann, J.I.; Frempong, F. International tourism in Ghana: A survey analysis of traveler motivations and perceptions. J. Hosp. Tour. Manag. 2016, 29, 176-183. [CrossRef]

4. Zhang, Y.; Peng, Y. Understanding travel motivations of Chinese tourists visiting Cairns, Australia. J. Hosp. Tour. Manag. 2014, 21, 44-53. [CrossRef]

5. Mctc. The development of inbound and outbound tourism in China. Yearb. China Tour. Stat. 2019, 1-3, 107-116.

6. Wtf. The development status of inbound tourism in China. Data Anal. Rep. China's Inbound Tour. 2019, 9, 277-281.

7. Seetaram, N. Immigration and international inbound tourism: Empirical evidence from Australia. Tour. Manag. 2012, 33, 1535-1543. [CrossRef]

8. Lv, X.; Li, C.; McCabe, S. Expanding theory of tourists' destination loyalty: The role of sensory impressions. Tour. Manag. 2020, 77, 104-126. [CrossRef]

9. Su, Y.-W.; Lin, H.-L. Analysis of international tourist arrivals worldwide: The role of world heritage sites. Tour. Manag. 2014, 40, 46-58. [CrossRef]

10. Deng, M.; Athanasopoulos, G. Modelling Australian domestic and international inbound travel: A spatialtemporal approach. Tour. Manag. 2011, 32, 1075-1084. [CrossRef]

11. Kuzey, C.; Karaman, A.S.; Akman, E. Elucidating the impact of visa regimes: A decision tree analysis. Tour. Manag. Perspect. 2019, 29, 148-156. [CrossRef]

12. Shi, $\mathrm{H}$. The efficiency of government promotion of inbound tourism: The case of Australia. Econ. Model. 2012, 29, 2711-2718. [CrossRef]

13. Song, H.; Van der Veen, R.; Li, G.; Chen, J.L. The Hong Kong tourist satisfaction index. Ann. Tour. Res. 2012, 39, 459-479. [CrossRef]

14. Handler, I. The impact of the Fukushima disaster on Japan's travel image: An exploratory study on Taiwanese travelers. J. Hosp. Tour. Manag. 2016, 27, 12-17. [CrossRef]

15. Mussalam, G.Q.; Tajeddini, K. Tourism in Switzerland: How perceptions of place attributes for short and long holiday can influence destination choice. J. Hosp. Tour. Manag. 2016, 26, 18-26. [CrossRef] 
16. Souiden, N.; Ladhari, R.; Chiadmi, N.E. Destination personality and destination image. J. Hosp. Tour. Manag. 2017, 32, 54-70. [CrossRef]

17. Mutinda, R.; Mayaka, M. Application of destination choice model: Factors influencing domestic tourists destination choice among residents of Nairobi, Kenya. Tour. Manag. 2012, 33, 1593-1597. [CrossRef]

18. Leung, X.Y.; Wang, F.; Wu, B.; Bai, B.; Stahura, K.A.; Xie, Z. A social network analysis of overseas tourist movement patterns in Beijing: The impact of the Olympic Games. Int. J. Tour. Res. 2012, 14, 469-484. [CrossRef]

19. Chaulagain, S.; Wiitala, J.; Fu, X. The impact of country image and destination image on US tourists' travel intention. J. Destin. Mark. Manag. 2019, 12, 1-11. [CrossRef]

20. Mou, N.; Yuan, R.; Yang, T.; Zhang, H.; Tang, J.J.; Makkonen, T. Exploring spatiotemporal changes of city inbound tourism flow: The case of Shanghai, China. Tour. Manag. 2020, 76, 103955. [CrossRef]

21. Koc, E.; Altinay, G. An analysis of seasonality in monthly per person tourist spending in Turkish inbound tourism from a market segmentation perspective. Tour. Manag. 2007, 28, 227-237. [CrossRef]

22. Marais, M.; du Plessis, E.; Saayman, M. A review on critical success factors in tourism. J. Hosp. Tour. Manag. 2017, 31, 1-12. [CrossRef]

23. Yu-Shan, W. The impact of crisis events and macroeconomic activity on Taiwan's international inbound tourism demand. Tour. Manag. 2009, 30, 75-82. [CrossRef]

24. Gozgor, G.; Lau CK, M.; Zeng, Y.; Lin, Z. The effectiveness of the legal system and inbound tourism. Ann. Tour. Res. 2019, 76, 24-35. [CrossRef]

25. Yang, X.-Z.; Gu, C.-L.; Wang, Q. Systematic analysis of tourism flow driving force. Geogr. Res. 2011, 30, $23-36$.

26. Chen, Y.; Li, X.R. Does a happy destination bring you happiness? Evidence from Swiss inbound tourism. Tour. Manag. 2018, 65, 256-266. [CrossRef]

27. Feng, X.; Sun, X.; Yu, Q. Balance between tourist season and tourist seasonality: Research review and enlightenment. Tour. Trib. 2014, 29, 92-100. [CrossRef]

28. Zhang, J.; Du, J.; Zhou, Y. Study on the spatial structure of natural tourist destination market-taking Jiuzhaigou and comparative scenic spot as an example. J. Geogr. 1999, 54, 357-365.

29. Lu, L.; Xuan, G.; Zhang, J.; Yang, X.; Wang, D. Seasonal comparison of coastal and mountainous tourist destinations: A case study of Sanya, Beihai, Putuo Mountain, Huangshan and Jiuhua Mountain. J. Geogr. 2002, 57, 731-740.

30. Wang, D.; Chen, T.; Lu, L.; Wang, L. The high-iron effect of the spatial structure of domestic tourist market in tourist destination. Geography 2013, 33, 797-805. [CrossRef]

31. Liu, Z.; Gu, Z.; Wang, N. The influence of leisure time constraint on the spatial structure of domestic tourist market. Geogr. Res. 2013, 32, 1738-1748. [CrossRef]

32. Garín-Mun, T. Inbound international tourism to Canary Islands: A dynamic panel data model. Tour. Manag. 2006, 27, 281-291. [CrossRef]

33. Tokumura, S. A study on the segmentation of Japan's international tourist market. J. Geogr. 2007, 22, 24-30.

34. Hsu, T.K.; Tsai, Y.F.; Wu, H.H. The preference analysis for tourist choice of destination: A case study of Taiwan. Tour. Manag. 2009, 30, 288-297. [CrossRef]

35. Hong, S.K.; Kim, J.H.; Jang, H.; Lee, S. The roles of categorization, affective image and constraints on destination choice: An application of the NMNL model. Tour. Manag. 2006, 27, 750-761. [CrossRef]

36. Chi, C.G.Q.; Qu, H. Examining the structural relationships of destination image, satisfaction and destination loyalty: An integrated approach. Tour. Manag. 2008, 29, 624-636. [CrossRef]

37. Zhang, H.; Fu, X.; Cai, L.A.; Lu, L. Destination image and tourist loyalty: A meta-analysis. Tour. Manag. 2014, 40, 213-223. [CrossRef]

38. Wong, C.U.I.; Qi, S. Tracking the evolution of a destination's image by text-mining online reviews -the case of Macau. Tour. Manag. Perspect. 2017, 23, 19-29. [CrossRef]

39. Eugenio-Martin, J.L.; Campos-Soria, J.A. Climate in the region of origin and destination choice in outbound tourism demand. Tour. Manag. 2010, 31, 744-753. [CrossRef]

40. Nicolau, J.L. Differentiated price loss aversion in destination choice: The effect of tourists' cultural interest. Tour. Manag. 2011, 32, 1186-1195. [CrossRef]

41. Gholipour, H.F.; Tajaddini, R.; Nguyen, J. Happiness and inbound tourism. Ann. Tour. Res. 2016, 57, $251-253$. [CrossRef]

42. Gnoth, J. Tourism motivation and expectation formation. Ann. Tour. Res. 1997, 24, 283-304. [CrossRef] 
43. Kozak, M. Comparative analysis of tourist motivations by nationality and destinations. Tour. Manag. 2002, 23, 221-232. [CrossRef]

44. Pesonen, J.; Komppula, R. Rural Wellbeing Tourism: Motivations and Expectations. J. Hosp. Tour. Manag. 2010, 17, 150-157. [CrossRef]

45. Ross, E.L.D.; Iso-Ahola, S.E. Sightseeing tourists' motivation and satisfaction. Ann. Tour. Res. 1991, 18, 226-237. [CrossRef]

46. Devesa, M.; Laguna, M.; Palacios, A. The role of motivation in visitor satisfaction: Empirical evidence in rural tourism. Tour. Manag. 2010, 31, 547-552. [CrossRef]

47. Park, D.B.; Yoon, Y.S. Segmentation by motivation in rural tourism: A Korean case study. Tour. Manag. 2009, 30, 99-108. [CrossRef]

48. Yoon, Y.; Uysal, M. An examination of the effects of motivation and satisfaction on destination loyalty: A structural model. Tour. Manag. 2005, 26, 45-46. [CrossRef]

49. Zhang, H.; Zhang, J.; Cao, J.; Liu, C.; Shi, C.; Yang, Y. Research on discrete model of tourist destination selection based on travel motivation. J. Geogr. 2008, 23, 43-48. [CrossRef]

50. Li, W.; Hu, J.; Lu, R.; Cheng, S.; Xing, Z.; Zhou, R. A study on the temporal and spatial distribution of tourist flow in special period of tourism destination. Econ. Geogr. 2013, 33, 180-186.

51. Alsumairi, M.; Tsui, K.W.H. A case study: The impact of low-cost carriers on inbound tourism of Saudi Arabia. J. Air Transp. Manag. 2017, 62, 129-145. [CrossRef]

52. Khan, S.A.R.; Qianli, D.; SongBo, W.; Zaman, K.; Zhang, Y. Travel and tourism competitiveness index: The impact of air transportation, railways transportation, travel and transport services on international inbound and outbound tourism. J. Air Transp. Manag. 2017, 58, 125-134. [CrossRef]

53. Kim, J.; Lee, C.K. Role of tourism price in attracting international tourists: The case of Japanese inbound tourism from South Korea. J. Destin. Mark. Manag. 2017, 6, 76-83. [CrossRef]

54. Deng, N.; Liu, J.; Dai, Y.; Li, H. Different cultures, different photos: A comparison of Shanghai's pictorial destination image between East and West. Tour. Manag. Perspect. 2019, 30, 182-192. [CrossRef]

55. Liu, Y.; Huang, K.; Bao, J.; Chen, K. Listen to the voices from home: An analysis of Chinese tourists' sentiments regarding Australian destinations. Tour. Manag. 2019, 71, 337-347. [CrossRef]

56. Xu, X.; Reed, M. Perceived pollution and inbound tourism in China. Tour. Manag. Perspect. 2017, 21, 109-112. [CrossRef]

57. Guo, S.; Jiang, Y.; Long, W. Urban tourism competitiveness evaluation system and its application: Comparison and analysis of regression and classification methods. Procedia Comput. Sci. 2019, 22, 162. [CrossRef]

58. Gooroochurn, N.; Sugiyarto, G. Competitiveness indicators in the travel and tourism industry. Tour. Econ. 2005, 11, 25-46. [CrossRef]

59. Su, F. Research on the difference of urban tourism competitiveness in Huaihai economic zone based on the theil coefficient. J. Baoshan Univ. 2018, 37, 92-98. [CrossRef]

60. Illeris, S. The Service Economy: A Geographical Approach; John Wiley \& Sons Ltd.: Hoboken, NJ, USA, 1996; pp. 169-170.

(C) 2020 by the authors. Licensee MDPI, Basel, Switzerland. This article is an open access article distributed under the terms and conditions of the Creative Commons Attribution (CC BY) license (http://creativecommons.org/licenses/by/4.0/). 